acompanhadas de disturbios circulatorios, confirma, ainda uma vez, que, no numero dos symptomas por que se costumam exteriorisar os tumores da fossa cerebral média, não se nos deparam os decorrentes da hypertensão craneana.

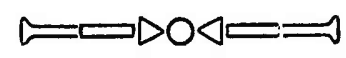

\title{
A anesthesia rachidiana
}

Por J. FERREIRA SANTOS, 4.o annista de Medicina.

A anesthesia por via intra-rachidiana, cujos successos são tão conhecidos, originou-se dos trabalhos de Leonardo Corning, medico americano, o qual, em 1885, tentou pela primeira vez a analgesia cirurgica pela via rachidiana, injectando cocaina no espaço inter-vertebral. Este illustre autor não chegou a fazer a injecção intra-rachidiana, temendo o ferimento da medulla.

Estava, pois, dado o primeiro passo para o novo processo de anesthesia, quando Bier, professor da Universidade de Kiel (actualmente em Berlim), em Abril de 1889, apresentou uma monographia sobre tão importante assumpto, acompanhada de observações, na qual mostrava ter feito resecções osseas no membro inferior, sem a menor dôr, applicando uma injecção rachidiana de cocaina. Bier, afim de demonstrar o effeito da cocainisação da medulla, fez experiencias em si mesmo e no seu assistente Hildebrandt.

Por esse mesmo tempo Sicard, em França, apresentava trabalhos identicos; todavia, só de 1899 em diante, é que a rachi-anesthesia tomou incremento devido aos estudos do emerito professor Tuffier, o qual naquelle referido anno, operou uma mulher internada em sua clinica, que era portadora de um enorme sarcoma reincidivado da coxa, com a rachi-cocainisação, tendo a anesthesia durado mais de uma hora e com o resultado post-operatorio maravilhoso. Continuando com as suas pesquizas, Tuffier, em 1900, já praticava intervenções cirurgicas no perineo, bexiga, vagina, re- 
cto e abdomen, tendo mesmo feito a ablação de um rim com a rachi-cocainisação.

Foi de sua escola que se irradiou o novo methodo por todo o mundo scientifico, e, não devemos olvidar que em São Paulo, o primeiro a introduzil-o nos serviços hospitalares, foi o nosso egregio Mestre e presado amigo Prof. dr. Oliveira Fausto, o qual obteve brilhante resultado, como se vé do seu trabalho publicado na "Revista Medica de S. Paulo", em 31 de Maio de 1901, n. 10, pag. 162 e transcripto e elogiado pelo Prof. Desfosses, na Presse Médicale de Paris, n. 60 , pag. 43, de 27 de Julho de 1901, trabalho esse acompanhado de tres observações sobre a nova anesthesia, applicada no serviço clinico do dr. Amarante Cruz, em nosso Hospital de Misericordia.

A rachi-anesthesia, embora tão bem applicada, teve uma certa relutancia na sua acceitação em nosso meio, mas, afinal, venceu e é hoje empregada em larga escala.

\section{INSTRUMENTAL DA RACHI-ANESTHESIA}

Seringa de Pravaz; agulha de platina iridiada de $8 \mathrm{cms}$. de comprimento e de um diametro interno de $6 \mid 10$ de m.m., mais ou menos; empôlas de cocaina, novocaina, tropococaina ou estovaina.

Os allemães empregam de preferencia a tropococaina, visto a mesma ter a vantagem de não paralysar os nervos motores e agir tão sómente sobre os sensitivos, donde resulta que o paciente tem todos os movimentos.

No serviço do Prof. Bier, de Berlim, é usada a tropococaina a $\left.5^{\circ}\right|^{\circ} \mathrm{em}$ sôro physiologico, associada á solução de adrenalina ao millesimo. A addição da adrenalina apresenta duas vantagens: impede a entrada subita da tropococaina na circulação e limita a sua absorpção.

Na clinica do Prof. Baldo Rossi, de Milão, tem sido feita com grande exito, a rachi-anesthesia com uma mistura de estovaina, novocaina e estrychnina, em soluções separadas, de modo a não se injectar mais de 4 centigrms. de estovaina, 1 centigrm. de novocaina e 1 milligrm. de estrychnina. 0 
Prof. Rossi em uma estatistica publicada em 1910, apresentou tres mil observações com a analgesia acima, sem contar um só insuccesso.

Jonnesco, de Bukarest, o grande precursor da anesthesia rachidiana alta, faz uso da estovaina (5 a 6 centigrms.) associada á estrychnina (1 a 2 milligrms.)

$\mathrm{Na} 1 .^{\mathrm{a}}$ Clinica Cirurgica da Faculdade de Medicina e Cirurgia de 'São Paulo, a cargo do nosso dedicado Mestre Prof. Dr. Antonio Candido de Camargo, empregamos a rachi-anesthesia, injectando de 5 a 8 centigrms. de estovaina. A estovaina usada nos é fornecida pela Pharmacia da Santa Casa, em empôlas, com a seguinte dosagem:

Estovaina......... 10 centigrms.

Agua distillada...... 1 c.c. .

Após havermos procedido a rachi-estovainisação, submettemos o doente a uma injecção intra-muscular de 2 milligrms. de estrychnina.

Damos preferencia á estovaina, visto ser ella duas a tres vezes menos toxica que a cocaina e dispôr de um poder anelgesico igual a este ultimo alcaloide. A acção da estovaina sobre os vasos é neutra, quer dizer, não é nem vaso-constrictora, nem vaso-dilatadora.

\section{TECHNICA DA RACHI-ANESTHESIA}

Podemos fazel-a em decubitus lateral ou mantendo o doente sentado no bordo da mesa - preferimos esta ultima.

Sentado o doente, fazemos com que elle incline ligeiramente o tronco para frente, tendo as coxas afastadas e os braços apoiados sobre as mesmas. (Fig. 1). Fazemos então a desinfecção da região com tintura de iodo, tendo tambem o cuidado de fazer a nossa rigorosa asepsia, e procedemos a punç̧ão no $4 .^{\circ}$ espaço lombar, espaço esse que corresponde ao ponto da espinha por onde passa a linha que une as duas cristas iliacas (Fig. 2). No momento de effectuarmos a punç̧ão, devemos mandar o paciente inclinar-se para fren- 
te, afim de que o espaço entre as laminas vertebraes seja o maior possivel. A agulha vence respectivamente a pelle, camada musculo-aponevrotica, penetra no espaço inter-vertebral, atravessa o ligamento amarello e as meninges (duramadre e arachnoide) penetrando, então, no espaço arachnoideu. $O$ operador percebe quando a agulha transpõe esse espaço, pois que a sente vencer toda a resistencia. Feita a puncção, vemos o liquido cephalo-rachidiano brotar pela agulha, limpido, gotta á gotta, ou com maior pressão. Não devemos nos assustar caso esse liquido apresente uma coloração vermelha, pois é passageira e devido á picada de alguma venula intra-dura-madre. Vendo então o liquido jorrár, passamos a injectar a estovaina; adaptando a seringa á agulha, a pressão faz com que o embulo da seringa seja projectado para traz, deixando o liquido misturar-se com a estovaina, o que resulta o turvamento da solução. Finalmente, injectamos com lentidão e em seguida retiramos a agulha e deitamos o doente.

Não devemos injectar mais de 8 centigrms. de estovaina, quantidade essa sufficiente mesmo para as intervenções mais demoradas.

E' de maxima importancia que o doente esteja em jejum, quando procedemos a rachi-anesthesia.

\section{RESULTADO DA INJECÇÃO}

A anasthesia se manifesta em geral tres a cinco minutos após, accusando o doente a sensação de furmigamento no membro inferior e perdendo logo em seguida, a sensibilidade da região infra-diaphragmatica. A anesthesia dura em geral uma hora a uma hora e meia.

\section{PHENOMENOS OBSERVADOS DURANTE A ANESTHESIA}

Os doentes apresentam algumas vezes: - mal estar, sensação de sêde, nauseas, pallidez da face, suores frios, vomitos e relaxamento do esphincter anal. 
Não devemos nos inquietar muito com esses phenomenos: são em geral passageiros e, dado que persistam, procederemos á injecção intra-muscular de estrychnina de 2 milligrms.

Qual a causa de semelhantes phenomenos? Em geral defeito de technica, que consiste na injecção de mais de 8 centigrms. de estovaina.

\section{ACCIDENTES OBSERVADOS DEPOIS DA ANESTHESIA}

Cephaléa e retenção de urina, sendo que a ultima póde persistir de 24 a 48 horas, tornando-se necessario a sondagem.

\section{ACCIDENTES MORTAES IMMEDIATOS}

Observamos tão sómente um, sendo que Tuffier e Desfosses, no seu trabalho intitulado "Petite Chirurgie Pratique", citam seis casos, porém, todos em doentes idosos e em estado lastimavel.

Afim de justificar a nossa confiança na rachi-anesthesia, juntamos a estatistica das operações praticadas com a rachi-estovainisação, durante o nosso estadio hospitalar na 1." Enfermaria de Cirurgia-Homens da Santa Casa de São Paulo, em os annos de 1914, 1915 e 1916.

$$
\text { I - HERNIAS }
$$

243 operações de hernias inguinaes $\left\{\begin{aligned} 219 & \text { hernias simples } \\ 19 & \text { hernias duplas } \\ 5 & \text { hernias estranguladas. }\end{aligned}\right.$

$$
\text { II - ABDOMEN }
$$

5 operảcões no abdomen....... 


\section{III - APPARELHO URINARIO}

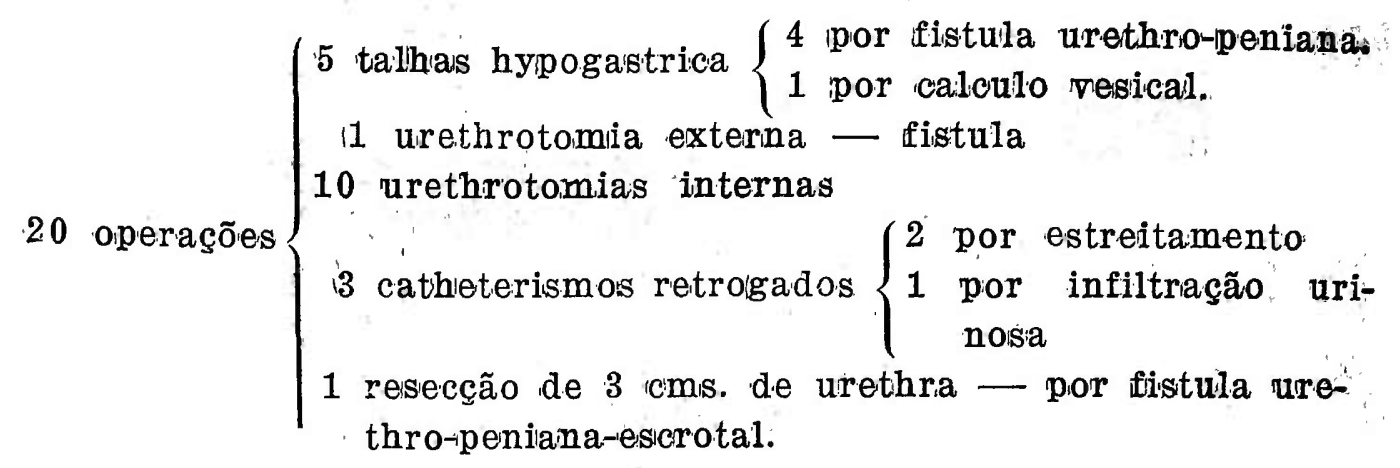

\section{IV - PERINEO - ANUIS - RECTO}

42 operações

3 incirsões e drenagens - abcessos perineaes.

5 thermocauterisaçõe $\left\{\begin{array}{l}1 \text { por prolapso do recto. } \\ 4 \text { por condylomas anaes }\end{array}\right.$

4 debridamentos - fistula do anus.

10 delbridamentos e curetagens - fistulas do anus.

18 dilatações e thermocauterisações-hemorrhoidas.

1 operação de Whitehead - hemorrthoidas.

1 esvasiamento pelo recto - fiecaloma.

\section{$\mathrm{V}$ - BOLISIAIS - PEINIS - PROISTAATA}

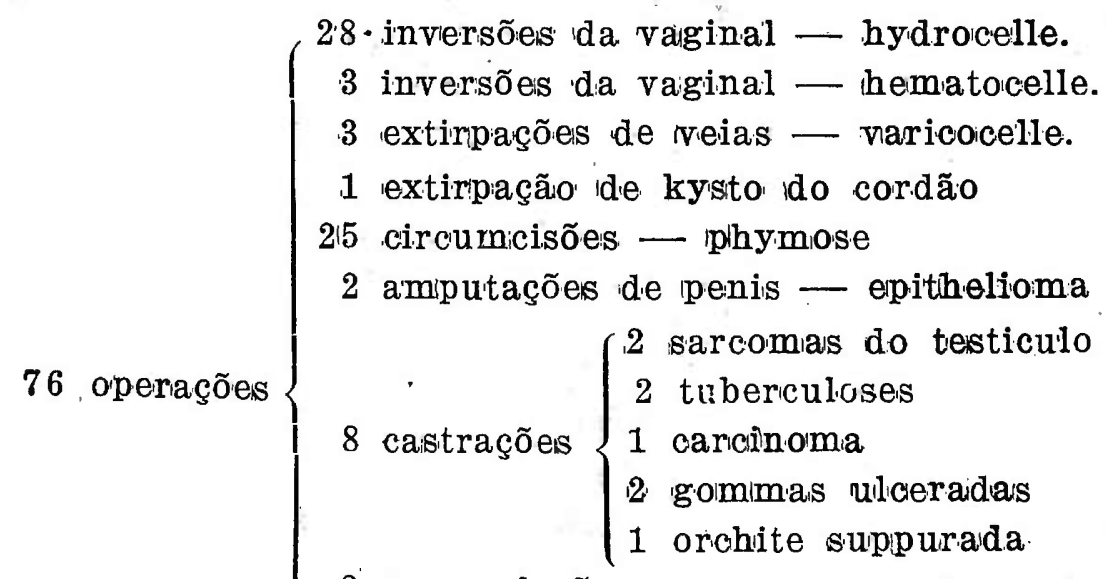

2 emasiculações - neoplasma do penis

2 prostatectomias $\begin{cases}1 & \text { hypertrophia } \\ 1 & \text { neoplasma }\end{cases}$

2 incisões e drenagens - abcessos da prostata.

$$
\text { VI — REGIÃIO ISAICRA }
$$

2 operações - 2 extippações -- kysto idermoide. 


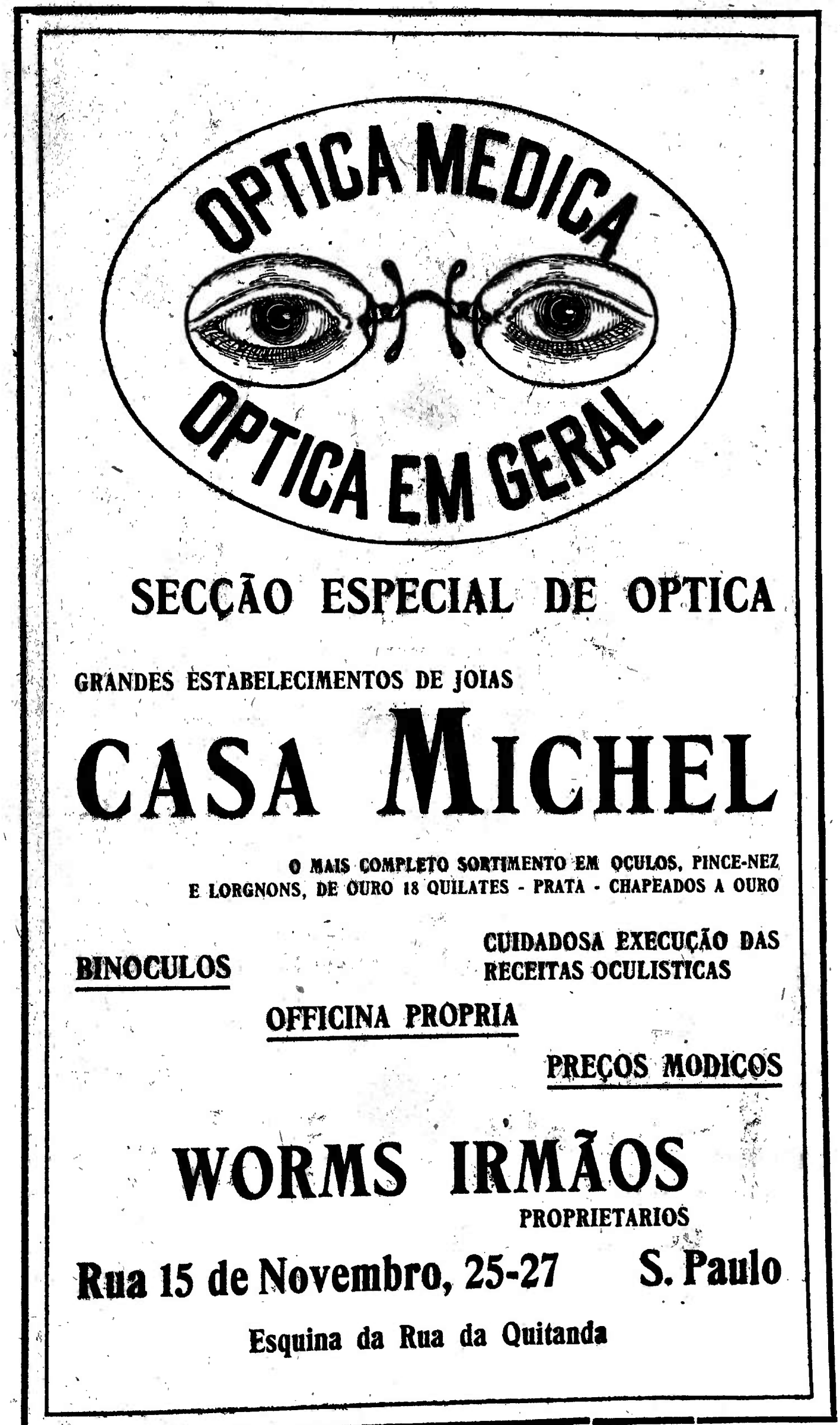




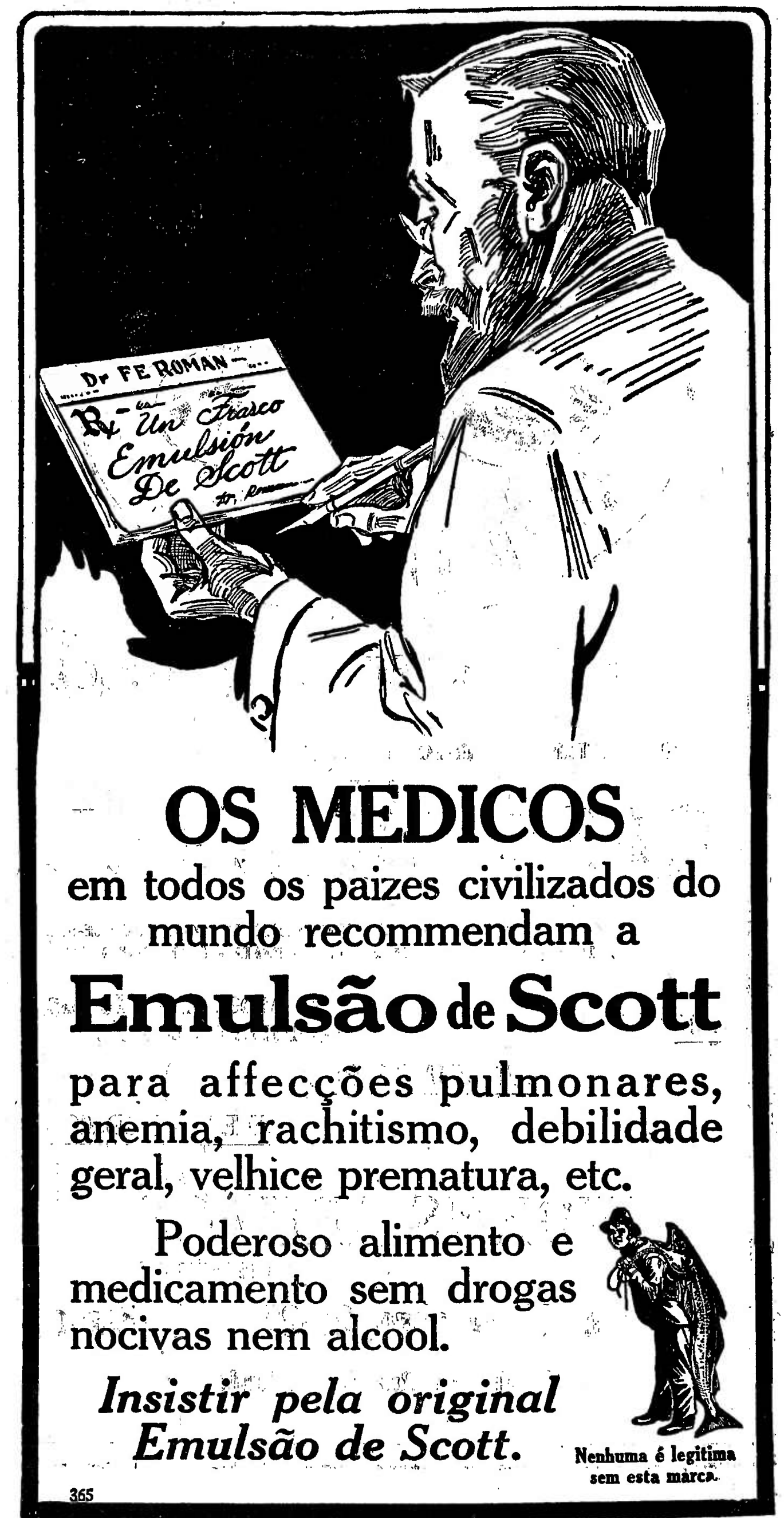


VII - ICOXA

16

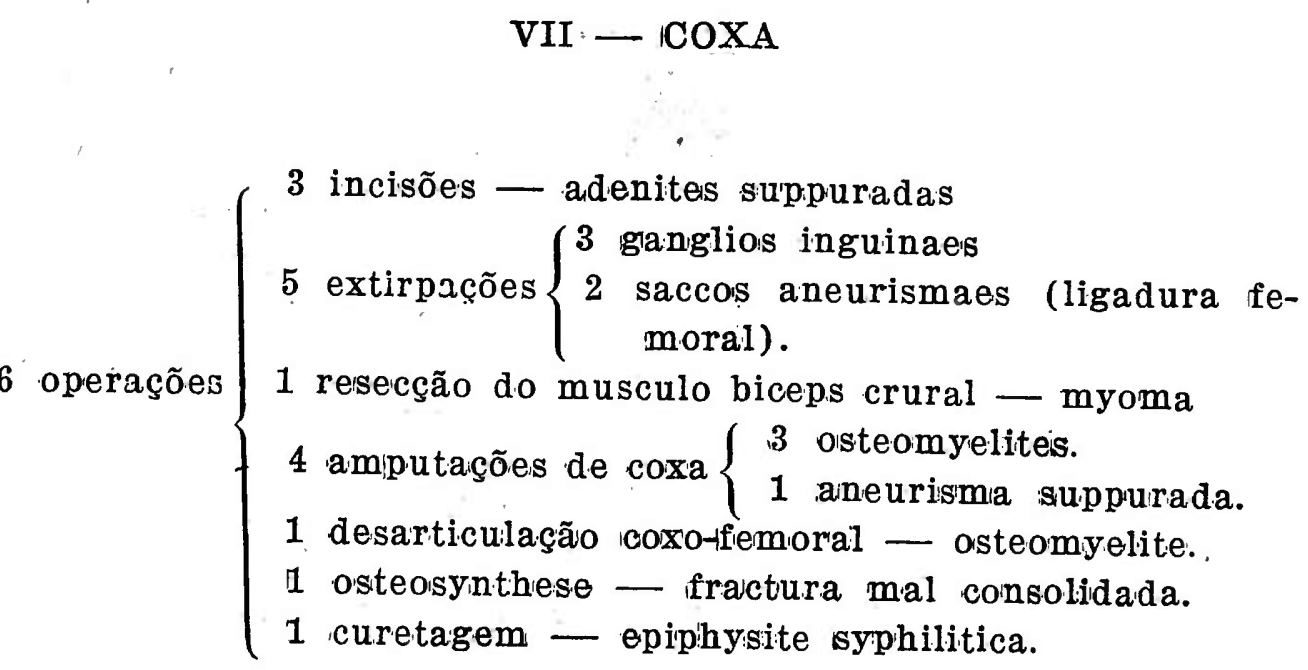

VIII - JOELHO

7 operações $\left\{\begin{array}{l}1 \text { arthrotomia }- \text { arthrite suppurada } \\ 4 . \text { “cerclages" Ida rotula - fractura } \\ 1 \text { osteotomia IMac Ewen - genu valgum } \\ 1 \text { extirpação sacco aneurismal - poplitea. }\end{array}\right.$

$$
\text { IX - PERNA }
$$

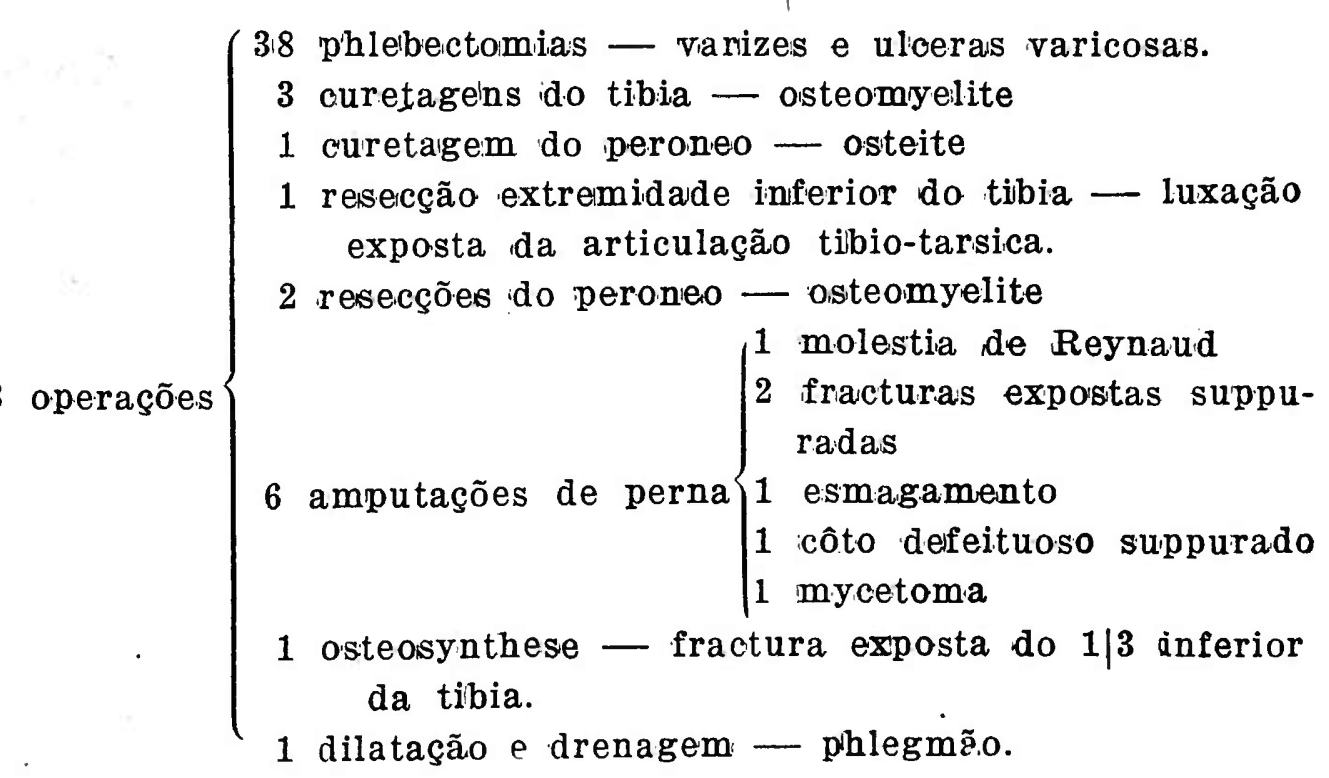




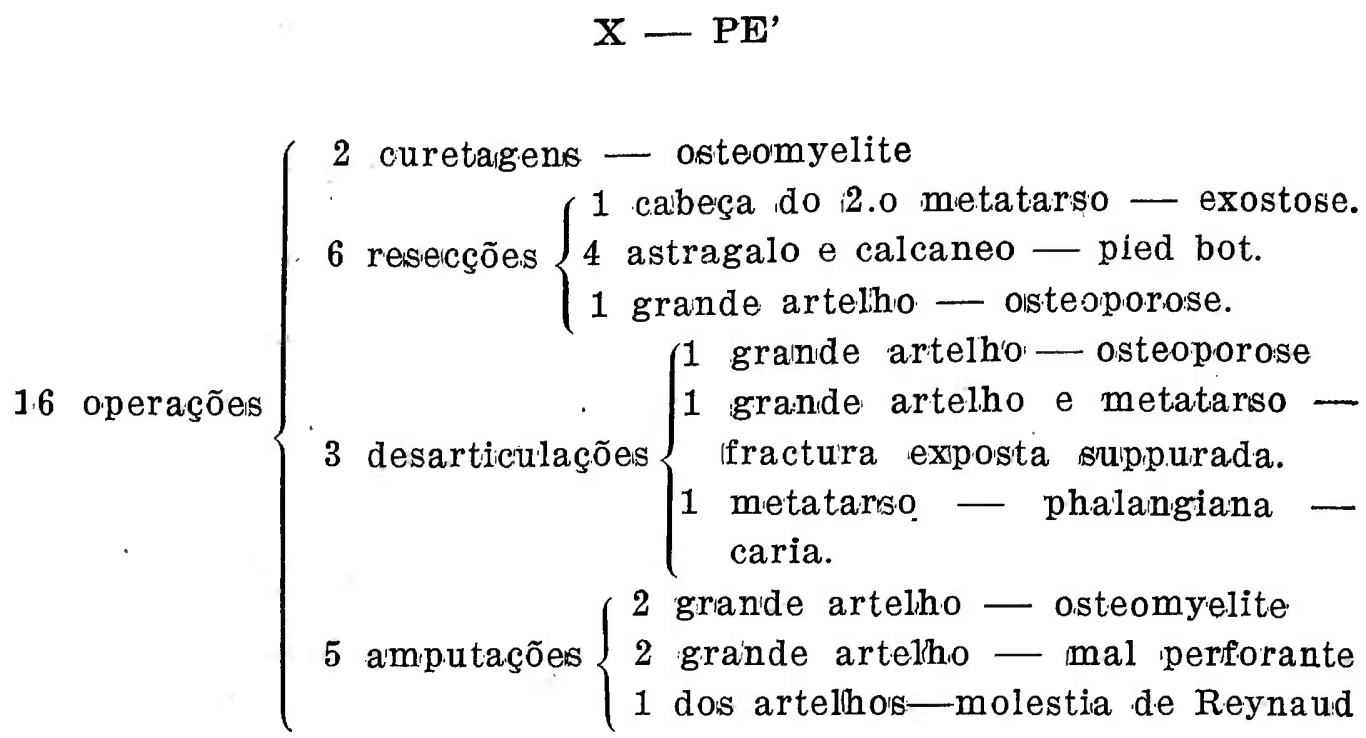

Em face da nossa estatistica vemos que foram praticadas quatrocentas e oitenta (480) intervenções com a anesthesia rachidiana, sendo que dessas 444 foram executadas no serviço clinico do nosso distincto Mestre Dr. Carlos Botelho, por elle e pelos Professores Drs. Meira Filho e Montenegro e pelo Dr. Salles Gomes Junior, e 36 na 1. ${ }^{\text {a }}$ Clinica Cirurgica da Faculdade de Medicina e Cirurgia de S. Paulo, a cargo do nosso emerito Mestre e Chefe Professor Dr. Antonio Candido de Camargo, por si ou por seus substitutos, Professores Drs. Oliveira Fausto e Zeferino do Amaral.

Em todas essas 480 intervenções, só procedemos uma vez a rachi-anesthesia alta, tão aconselhada por Jonnesco, não obtivemos bom resultado, sem que o mesmo, entretanto, fosse funesto.

Em nossa estatistica contamos com quatro insuccessos fataes, que passamos a commentar:

1) P. V. - 18 annos, italiano, solteiro. Diagnostico Hernia inguinal esquerda estrangulada. Foi feita a rachianesthesia com 1 c.c. de solução de estovaina á $\left.10^{\circ}\right|^{\circ}$. 0 doente accusou mal estar logo após, acompanhado de nauseas e suores frios, vindo a fallecer na enfermaria duas horas depois. 
A ANESTHESIA RACHIDIANA

117

X. T

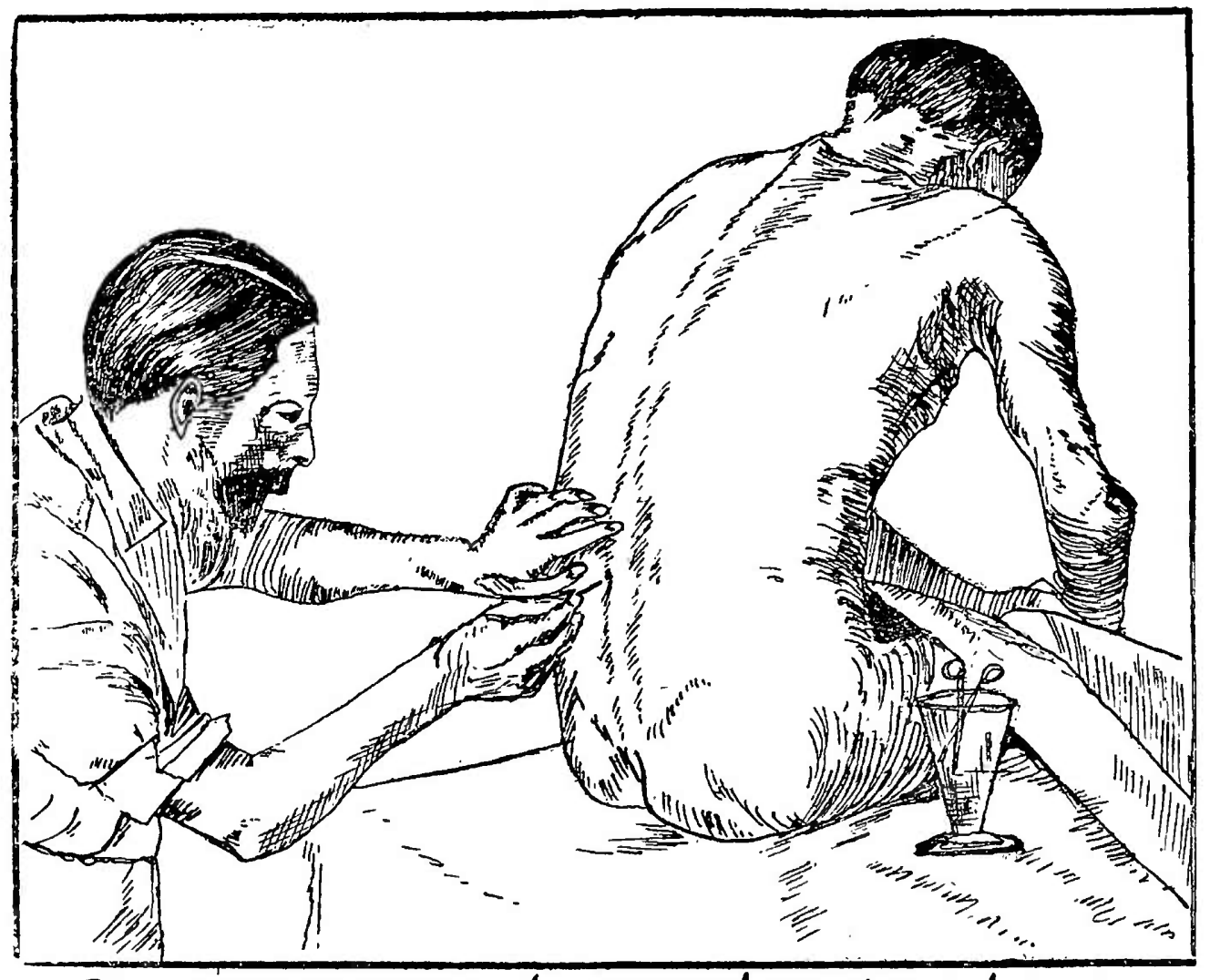

- Posuçá do operador e do operando auproceder, - Re

Fig. 1

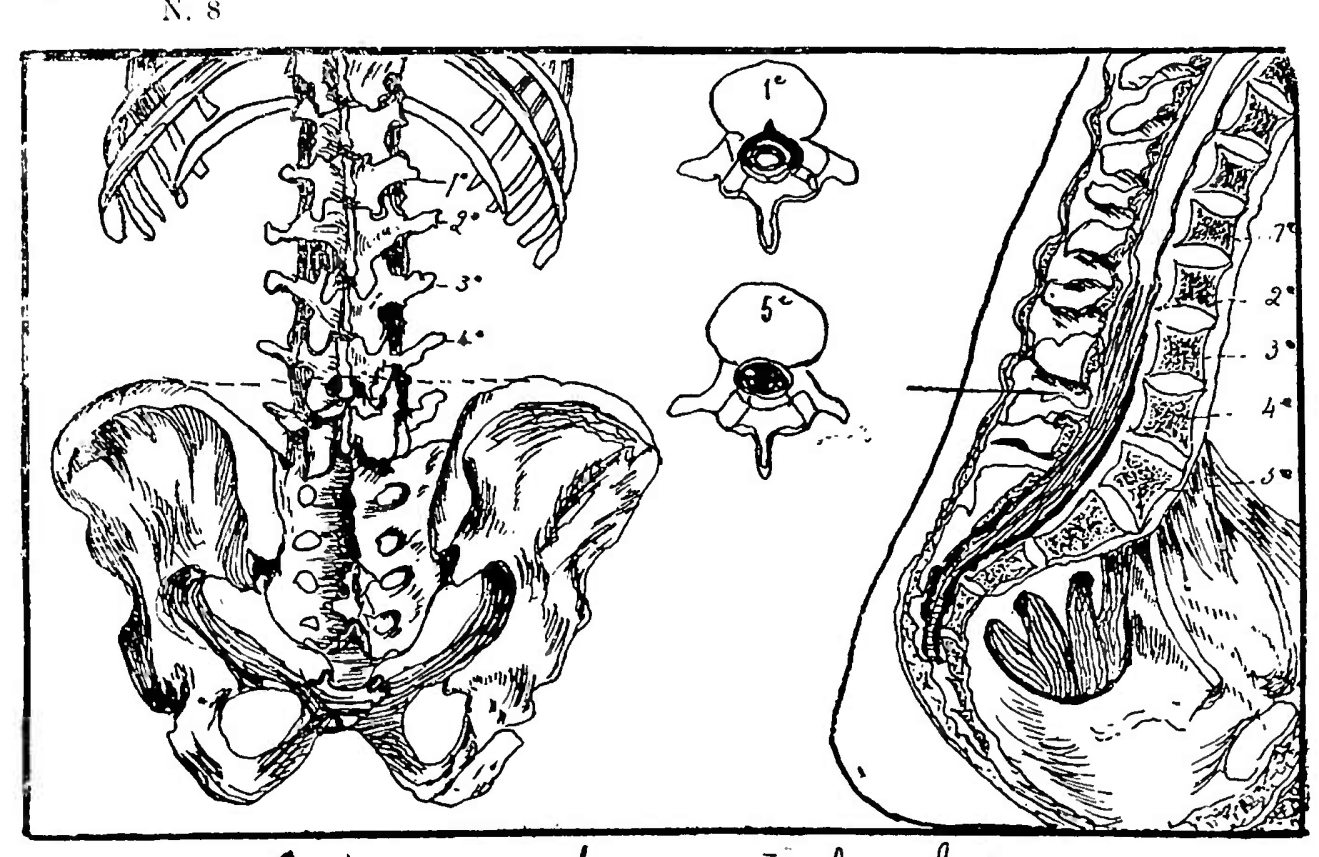

- Schema da regiás lombar

$F \cdot g \cdot 2$

(Vuffer e Desforses) 

2) E. B. - 20 annos, italiano, solteiro, marcineiro. Diagnostico - Hernia inguinal esquerda. Rachi-estovainisação. Foi feita a cura da hernia pelo processo Girard, com a manobra de Barker. Falleceu 24 horas após a injecção. Foi feita a autopsia, tendo sido diagnosticado como causa mortis a broncho-pneumonia.

3) S. C. R. - 59 annos, brasileiro, casado, professor. Ha 5 annos que não conseguia urinar sem sonda. Ha 2 dias que não urina de forma alguma. Foram feitas duas puncções vesicaes. Operado foi feito a prostatectomia e catheterismo retrogado. Rachi-estovainisação. Falleceu dez dias depois da intervenção.

4) P. O. G. - 15 annos, brasileiro, solteiro, sem profissão - Ha nove mezes que fracturou o femur esquerdo, ficando com ankylose do joelho. Ha tres semanas levou uma quéda, machucando o joelho, que começou a inchar consideravelmente. Operado, foi feita a incisão e evacuação do puz. Rachi-estovainisação. Falleceu um mez depois de septicemia.

Acabamos de ver que os tres ultimos doentes não succumbiram devido á anesthesia rachidiana pela estovaina, mas tão sómente o primeiro, tratando-se de um alcoolico inveterado.

Qual a causa da morte no primeiro caso?

Defeito de technica não houve, queremos crêr que o nosso doente apresentasse uma idiosyncrazia pela estovaina. Infelizmente não nos foi possivel fazer a necropsia.

Seja como fôr, vemos que em 480 intervenções, tivemos apenas uma morte pela nova anesthesia, o que é um resultado auspicioso, pois, bem sabemos, que o chloroformio e o ether, em mãos de anesthesiadores os mais experimentados, victimam em maior numero.

Concluimos, convencidos, mais uma vez, do grande valor anelgesico da rachi-estovainisação em todas as operações infra-diaphragmaticas, por isso que são patentes as suas vantagens, o que nos deve induzir a pratical-a sem receio de fracassos. 


\section{BIBLIOGRAPHIA}

Tuffier - L'Analgesie Chirurgicale par Voie Rachidienne. - L'Oeuvre Medico-Chirurgical. N. 24 - Masson \& Cie. Paris - 1901.

Oliveira Fausto - Contribuição á Rachi-Cocainisação. Revista Medica de S. Paulo, n. 10 - 1901.

Zeferino do Amaral - Valor Cirurgico da Rachi-Anesthesia. Imprensa Medica. Volume XIX, n. 10 - S. Paulo -1911 .

Monod et Vanverts - Traité de Technique Operatoire. Masson \& Cie. Paris - 1907.

Le Filliâtre - Anesthésie Générale par Rachicocainisation Lombo - Sacrée. - Gazette Medicale de Paris, n. $233-1914$.

Tuffier et Desfosses - Petite Chirurgie Pratique. - Masson \& Cie. Paris - 1914.

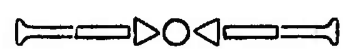

PEMTPHIGZIS FOLIACEZIS

(FOGO SELVAAEM)

Por f. TIBIRIÇA' FlbfHO, 3.० annisła de Medicina.

O pemphigus foliaceus, vulgarmente conhecido sob a denominação de fogo selvagem, é uma molestia da pelle, mais ou menos espalhada no interior do nosso Estado.

No decorrer das nossas lições de clinica dermatologica, tivemos a opportunidade de observar dois casos de pemphigus foliaceus, cujas notas principaes passaremos a descrever.

O pemphigus foliaceus é uma molestia terrivel e quasi sempre fatal. 